\title{
Review:
}

\section{Applications of artificial intelligence in intelligent manufacturing: a review*}

\author{
Bo-hu LI ${ }^{1}$, Bao-cun $\mathrm{HOU}^{2}$, Wen-tao $\mathrm{YU}^{\dagger 2}$, Xiao-bing $\mathrm{LU}^{2}$, Chun-wei YANG ${ }^{2}$ \\ ( ${ }^{1}$ The Second Academy of China Aerospace Science and Technology Corporation, Beijing 100039, China) \\ ( ${ }^{2}$ Beijing Aerospace Intelligent Manufacturing Technology Development Co., Ltd., Beijing 100039, China) \\ †E-mail: 09125035@bjtu.edu.cn \\ Received Dec. 14, 2016; Revision accepted Jan. 6, 2017; Crosschecked Jan. 8, 2017
}

\begin{abstract}
Based on research into the applications of artificial intelligence (AI) technology in the manufacturing industry in recent years, we analyze the rapid development of core technologies in the new era of 'Internet plus AI', which is triggering a great change in the models, means, and ecosystems of the manufacturing industry, as well as in the development of AI. We then propose new models, means, and forms of intelligent manufacturing, intelligent manufacturing system architecture, and intelligent manufacturing technology system, based on the integration of AI technology with information communications, manufacturing, and related product technology. Moreover, from the perspectives of intelligent manufacturing application technology, industry, and application demonstration, the current development in intelligent manufacturing is discussed. Finally, suggestions for the application of AI in intelligent manufacturing in China are presented.
\end{abstract}

Key words: Artificial intelligence; Intelligent manufacturing; Intelligent manufacturing system http://dx.doi.org/10.1631/FITEE.1601885

CLC number: TP18

\section{Introduction}

It is known that the new technological revolution and the new industrial revolution are gaining momentum. We believe that the new era of 'Internet plus artificial intelligence (AI)', characterized by ubiquitous networks, data-drivenness, shared services, cross-border integration, automatic intelligence, and mass innovation, is coming. The rapid development and fusion of new AI technologies with Internet technologies, new-generation information technologies, new energy technologies, materials technology, and biotechnology is an essential part of this new era, which in turn will enable the game-changing transformation of models, means, and ecosystems in terms of their application to the national economy, well-being, and national security.

\footnotetext{
Corresponding author

(D) ORCID: Wen-tao YU, http://orcid.org/0000-0002-9961-7582

(C) Zhejiang University and Springer-Verlag Berlin Heidelberg 2017
}

The manufacturing industry is a cornerstone of national economy, people's livelihood, and national security. The deep fusion of manufacturing technology with information communication technology, intelligent technology, and product-related expertise in particular, is enabling a game-changing transformation in terms of manufacturing models, manufacturing approaches, and its ecosystems.

\section{New development of artificial intelligence}

With the current popularization of the Internet, the universal existence of sensors, the emergence of big data, development of e-commerce, rise of the information community, and the interconnection and fusion of data and knowledge with society, physical space, and cyberspace, the information environment for AI development has been changed profoundly, leading to a new evolutionary phase: AI 2.0 (Pan, 2016). The emergence of new technologies also ena- 
bles a new phase of AI. The main features of AI 2.0 include the emergence of data-driven intuitive perception ability for intensive deep learning, Internetbased swarm intelligence, technology-oriented humanmachine hybrid augmented intelligence, as well as the rise of cross-media reasoning (Pan, 2016).

The continuous evolution of smart cities, intelligent medical care, intelligent transportation, intelligent logistics, intelligent robots, self-driving vehicles, smart-phones, intelligent toys, smart communities, and smart economies, to name but a few, provides a broad market demand and driving force in terms of new development of both AI technologies and applications.

\section{Artificial intelligence facilitates the devel- opment of intelligent manufacturing}

We believe that intelligent manufacturing is a new manufacturing model and the technical means by which new information and communication technology, intelligent science and technology, large manufacturing technology (including design, production, management, testing, and integration), system engineering technology, and related product technology are integrated with the whole system and lifecycle of product development. The life cycle of manufacturing thus uses autonomous sensing, interconnection, collaboration, learning, analysis, cognition, decision-making, control, and the execution of human, machine, material, and environmental information to enable the integration and optimization of various aspects of a manufacturing enterprise or group, including three elements (people/organizations, operational management, and equipment and technology) and five flows (information flow, logistics flow, capital flow, knowledge flow, and service flow). This facilitates production and provides a high efficiency, high quality, cost-effective, and environmentfriendly service for users, and therefore improves the market competitiveness of the manufacturing enterprise or group.

AI technology facilitates the development of new models, means, and forms, system architecture, and technology systems in the domain of intelligent manufacturing (Li et al., 2014; NMSAC and SACCAE, 2016).

\subsection{New models, means, and forms of intelligent manufacturing}

New models: Internet-based, service-oriented, collaborative, customizable, flexible, and socialized intelligent manufacturing system that is used to facilitate production and provide services to users.

New means: human-machine integrated smart manufacturing systems featuring digitalization, Internet of Things, virtualization, service, collaboration, customization, flexibility, and intelligence.

New form: intelligent manufacturing ecology with the characteristics of ubiquitous interconnection, data-drivenness, cross-border integration, autonomous intelligence, and mass innovation.

The deep integration of the application of these models, means, and forms will ultimately form an ecosystem of intelligent manufacturing (Fig. 1).

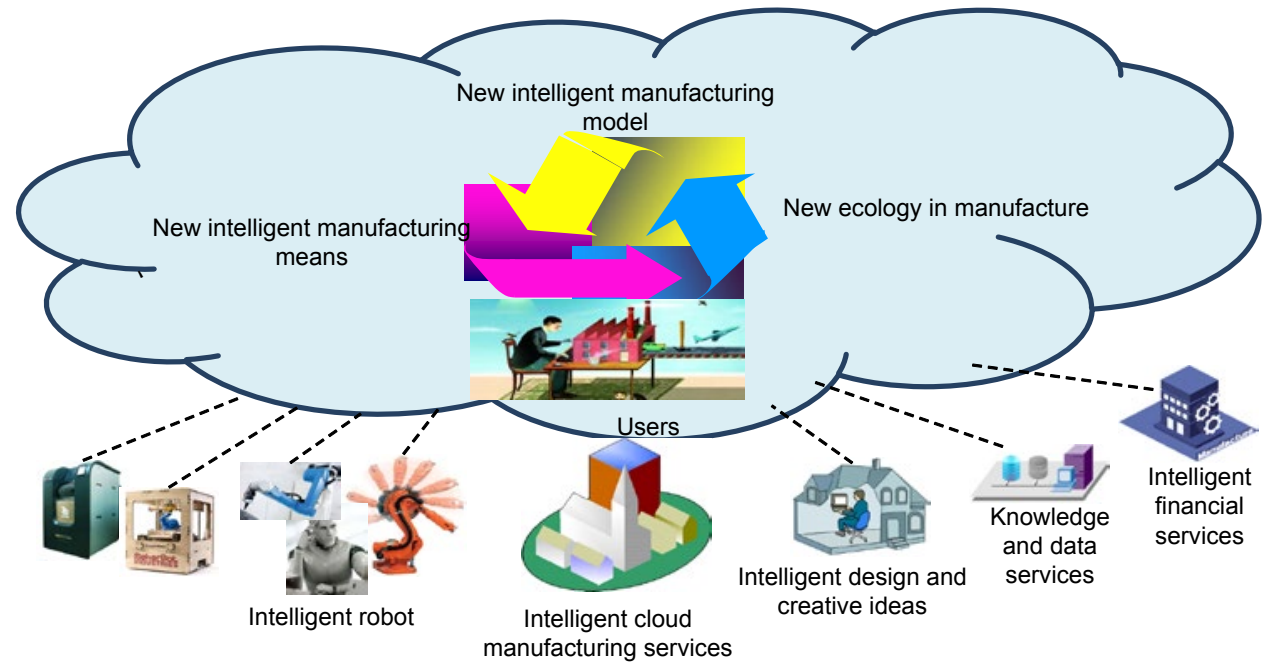

Fig. 1 New models, means, and forms of intelligent manufacturing 


\subsection{Intelligent manufacturing system architecture}

AI is applied in the field of intelligent manufacturing through the intelligent manufacturing system. The application of AI beyond the intelligent manufacturing system does not make any sense. Against the background of 'Internet plus AI', the intelligent manufacturing system is characterized by autonomous intelligent sensing, interconnection, collaboration, learning, analysis, cognition, decisionmaking, control, and execution of human, machine, material, environment, and information in the whole system and life cycle. The system consists of a resources/capacities layer, a ubiquitous network layer, a service platform, an intelligent cloud service application layer, as well as a security management and standard specification system (Fig. 2).

\subsubsection{Resources/capacities layer}

The resources/capacities layer includes manufacturing resources and manufacturing capacities, including: (1) hard manufacturing resources such as machine tools, robots, machining centers, computing equipment, simulation test equipment, materials and energies; (2) soft manufacturing resources such as models, (big) data, software, information, and knowledge in the manufacturing process; (3) manufacturing capacities of demonstration, design, production, simulation, experiment, management, sales, operation, maintenance, and integration in the manufacturing process as well as new digital, networked, and intelligent manufacturing interconnection products.

\subsubsection{Ubiquitous network layer}

The ubiquitous network layer consists of a physical network layer, a virtual network layer, a business arrangement layer, and an intelligence sensing/access layer.

1. The physical network layer includes mainly optical broadband, programmable switches, wireless base stations, communication satellites, ground base stations, aircraft, boats, etc.

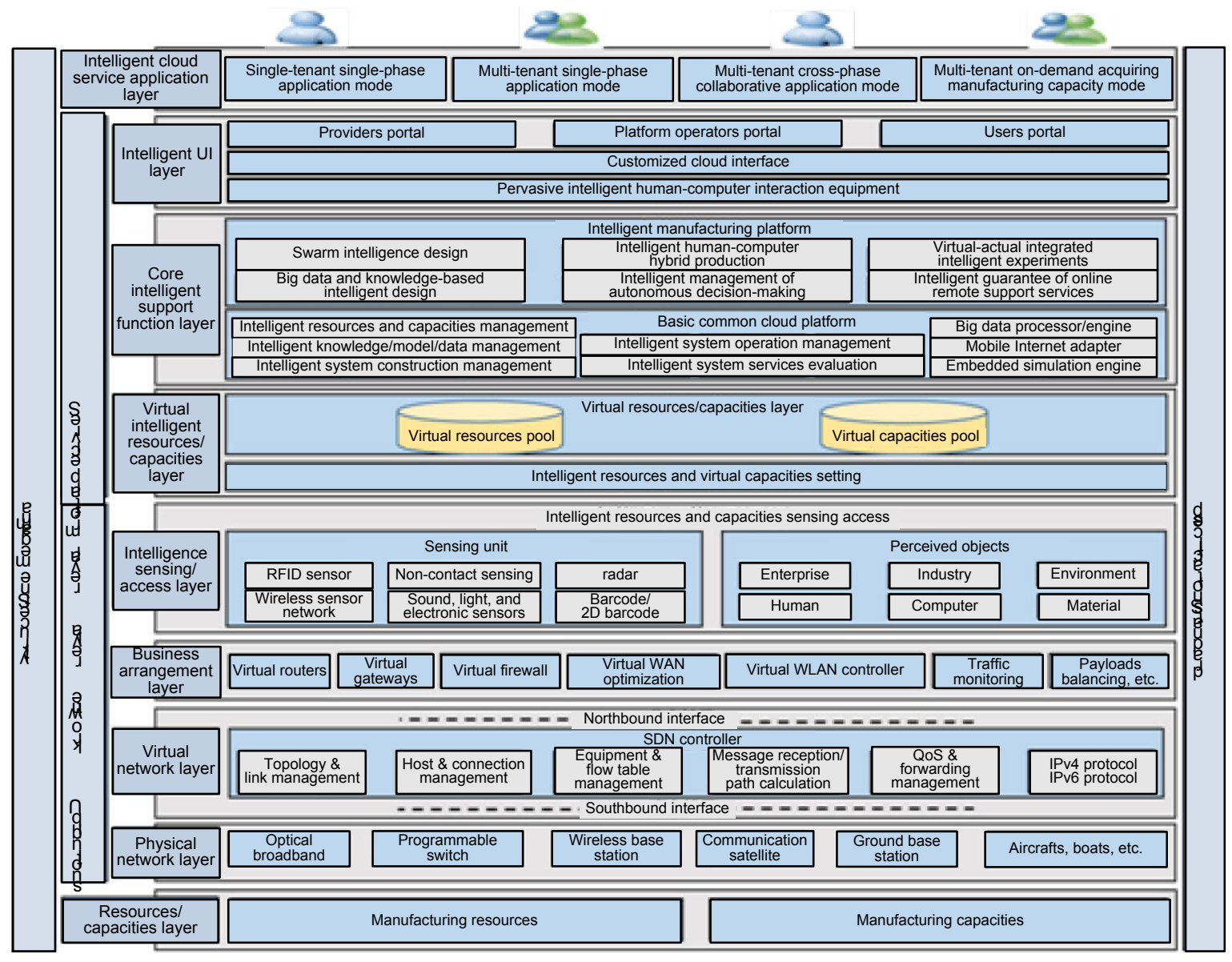

Fig. 2 Intelligent manufacturing system architecture 
2. The virtual network layer achieves an open network through southbound and northbound interfaces for topology management, host management, equipment management, message reception and transmission, quality of service (QoS) management, and IPv4/IPv6 protocol management.

3. The business arrangement layer provides the network functions in the form of software, through software and hardware decoupling and function abstracting to achieve rapid development and deployment of new businesses, and provides virtual router, virtual firewall, virtual wide area network (WAN) optimization and control, traffic monitoring, payloads balancing, etc.

4. The intelligence sensing/access layer senses objects such as enterprise, industry, human, machine, and material through the intelligent sensing units of a radio frequency identification (RFID) sensor, wireless sensor network, sound, light and electronic sensors/ equipment, bar code/2D bar code and radar, and transferring data and instructions through a network.

\subsubsection{Service platform layer}

The service platform layer consists of a virtual intelligent resources/capacities layer, a core intelligent support function layer, and an intelligent user interface (UI) layer.

1. The virtual intelligent resources/capacities layer provides an intelligent description and virtual setting of manufacturing resources/capacities to map the physical resources/capacities onto logical intelligent resources/capacities to form a virtual intelligent resources/capacities pool.

2. The core intelligent support function layer consists of a basic common cloud platform and an intelligent manufacturing platform, each respectively providing the base middleware functions such as intelligent system construction management, intelligent system operation management, intelligent system service evaluation, AI engine, and intelligent manufacturing functions such as swarm intelligence design, big data and knowledge-based intelligence design, intelligent human-computer hybrid production, virtual-actual combination of intelligent experiments, intelligent management of autonomous decision-making, and intelligent guarantee of online service remote support.

3. The intelligent UI layer pervasively supports intelligent terminal interaction equipment for service providers, operators, and users to achieve a customized user environment.

\subsubsection{Intelligent cloud service application layer}

The intelligent cloud service application layer highlights the role of the human/organization including four application modes: single-tenant singlephase application mode, multi-tenant single-phase application mode, multi-tenant cross-phase collaborative application mode, and multi-tenant on-demand acquiring manufacturing capacity mode. It also supports autonomous intelligent sensing, interconnection, collaboration, learning, analysis, prediction, decisionmaking, control, and execution of human, computer, material, environment, and information in the application of the intelligent manufacturing system.

\subsubsection{Security management and standard specifica-} tions

Security management and standard specifications include an autonomously controllable security protection system to ensure user identification, resource access, and data security of the intelligent manufacturing system, and a standard specifications system to standardize the application of the intelligent manufacturing system technology and the access, supervision, and evaluation of the platform.

Obviously, the intelligent manufacturing system is a kind of intelligent manufacturing networked services system based on a ubiquitous network and its combination, which integrates human/machine/goods/ environment/information and provides resources and capacities for intelligent manufacturing and

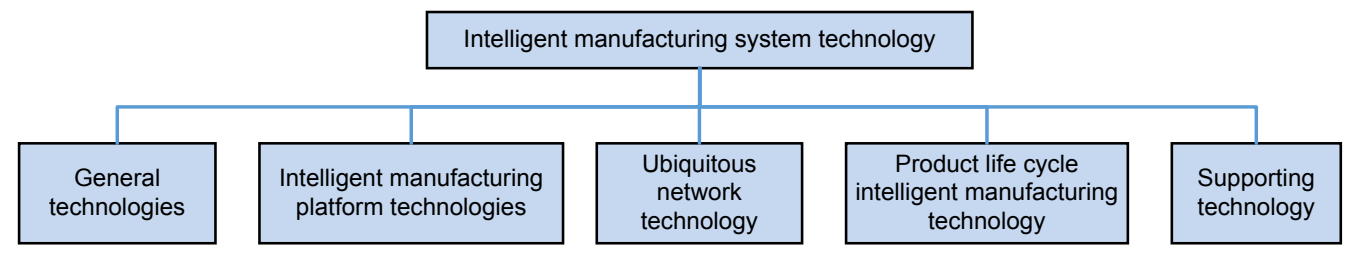

Fig. 3 The five types of intelligent manufacturing system technology 
on-demand services at any time and any place. It is a networked intelligent manufacturing system based on 'Internet (Cloud) plus resources and capacities for intelligent manufacturing' that integrates human, machine, and goods.

\subsection{Intelligent manufacturing technology system}

The intelligent manufacturing technology system consists mainly of general technology, basic platform technology, intelligent manufacturing platform technology, ubiquitous network technology, product life cycle intelligent manufacturing technology, and supporting technology (Fig. 3).

\subsubsection{General technology}

General technology includes mainly intelligent manufacturing architecture technology, softwaredefined networking (SDN) system architecture technology, space-air-ground system architecture technology, business model, enterprise modeling and simulation technologies of intelligent manufacturing services, system development and application technology, intelligent manufacturing security technology, intelligent manufacturing evaluation technology, and intelligent manufacturing standardization technology.

\subsubsection{Intelligent manufacturing platform technology}

Intelligent manufacturing platform technology includes mainly intelligent manufacturing oriented big data network interconnection technology, intelligent resources/capacity sensing and Internet of Things technology, intelligent resource/virtual capacity and service technology, intelligent service environment construction/management/operation/ evaluation technology, intelligent knowledge/model/ big data management, analysis and mining technology, intelligent human-computer interaction technology/ swarm intelligence design technology, intelligent design technology based on big data and knowledge, intelligent human-computer hybrid production technology, virtual-actual combination intelligent experiment technology, intelligent management technology of autonomous decision-making and intelligent guarantee technology of online remote support services.

\subsubsection{Ubiquitous network technology}

Ubiquitous network technology consists mainly of integrated fusion network technology and space- air-ground network technology.

3.3.4 Product life cycle intelligent manufacturing technology

Product life cycle intelligent manufacturing technology consists mainly of intelligent cloud innovation design technology, intelligent cloud product design technology, intelligent cloud production equipment technology, intelligent cloud operation and management technology, intelligent cloud simulation and experiment technology, and intelligent cloud service guarantee technology.

\subsubsection{Supporting technology}

Supporting technology consists mainly of AI 2.0 technology (Pan, 2016), information and communication technologies (such as big-data-based technology, cloud computing technology, modeling and simulation technology), new manufacturing technologies (such as 3D print technology, electrochemical machining technology), and professional technology of the manufacturing application area (professional technology of aviation, aerospace, shipbuilding, automobile, and other industries).

\section{Evaluation of the application of $\mathrm{Al}$ in intel- ligent manufacturing}

The integrated application of AI in the area of intelligent manufacturing may be evaluated by considering three aspects: application technology, industry, and application effect.

With application technology, the level and capacity of infrastructure construction, single applications, synergy applications, and business development need to be assessed. The evaluation of industry development covers intelligent products (products that may complete their tasks intelligently and autonomously) and intelligently connected products (intelligent products that may form an ecological network), intelligent industrial software, the development of hardware that supports intelligent design/ production/management/commissioning/security, and the development and operation of intelligent manufacturing systems at different levels of the intelligent manufacturing unit, intelligent workshop, intelligent factories, and intelligent industry. For application 
effects, it is suggested to focus the evaluation on the changes to competitiveness and the changes to social and economic benefits in order to measure the direct or indirect effects of the intelligent manufacturing system on enhancement of capability and economic benefits.

\section{Current global development of intelligent manufacturing}

\subsection{Overseas development}

Developed countries, such as the US and Germany in particular, have drafted innovative strategies and policies on intelligent manufacturing, such as the 'Advanced Manufacturing Partnership Plan' (2011) and 'Industrial Internet' (2012) in the US, and the 'Industry 4.0 Plan' (2013) in Germany.

In 2012, GE in the US proposed the concept of 'Industrial Internet', which can connect intelligent equipment, people, and data and analyze such data in an intelligent manner to enable smarter decisionmaking by humans and machines. The three major components of the Industrial Internet are intelligent equipment, intelligent systems and intelligent decision-making. The Industrial Internet may be seen as the circulation among, and interaction between, data, hardware, software, and intelligence. It can store, analyze, and visualize data acquired through intelligent equipment and networks for final intelligent decision-making based on intelligent information. The maximal potential of the Industrial Internet will be realized through the holistic integration of the three components-intelligent equipment, intelligent systems, and intelligent decisions - with machines, equipment sets, facilities, and system networks (Evans and Annunziata, 2012).

In 2013, Germany launched its Industry 4.0 plan, where the strategic idea of 'one core, two topics, three-dimensional integration, and eight plans' is proposed, with special emphasis on intelligent factories and intelligent production as the 'two major themes' for research. Cyber physical system (CPS) networks and the construction of correspondent intelligent equipment systems became its main concerns. In Industry 4.0, intelligent manufacturing systems can perceive and monitor massive data in real time, generated in the process of production, and realize intelligent analysis and decision-making so as to transform production mode into intelligent manufacturing, cloud-end collaborative manufacturing, and customer tailored production, and realize the integration of more production factors in a more scientific manner. The essence of Industry 4.0 is to realize the 'intelligent factory' based on the 'cyber physical system'. Production equipment will implement real-time sensing by integrating different sensors with precise process control through the network and data. For production management, a series of technologies will be adopted, which will constitute a service cloud and provide physical equipment with information perception, network communication, precise control, and remote coordination capabilities (Drath and Horch, 2014; Lasi et al., 2014; Wang, 2015; Ivanov et al., 2016).

It is obvious that the development of technologies, industries, and applications in intelligent manufacturing became the main concern in each country's strategic plan. Both the US and Germany are in leading positions in terms of their strategic plans.

CPS-based intelligent manufacturing technology in Germany has achieved milestone results, and Industrial Internet based intelligent manufacturing technology in the US has also accomplished initial outcomes. Germany focuses on the research of underlying technologies for manufacturers, such as intelligent sensing, wireless sensor networks, and CPSs, while the US prioritizes the IT technologies on the top layer such as cloud computing, big data, and virtual reality (Lee et al., 2015; Posada et al., 2015).

The intelligent manufacturing industries in Germany and the US have begun to take shape with the development of intelligent manufacturing system tools and platforms such as the industrial Internet platform Predix developed by GE in the US and the digital cloud service platform Sinalytics built by Siemens in Germany. Four core functions of Predix include security monitoring of networked assets, industrial data management, industrial data analysis, and cloud applications and mobility, which connect all types of industrial devices and suppliers to the cloud, providing asset performance management and operations optimization service. Siemens' Sinalytics platform can provide security communications and the integration and analysis of large amounts of machine-generated data, improving monitoring and 
optimization capabilities through data analysis and feedback for gas turbines, wind power generators, trains, buildings, and medical imaging systems. Intelligent Internet products, such as the intelligent Internet engine developed by GE, can connect aircraft engines to control systems. Sensors will gather data from the engine during its flight and transmit it to the ground for smart analysis so that engine operation conditions can be precisely detected and faults can be predicted to prompt proactive maintenance, improving the safety and service life of the engine (Yang, 2015; Li, 2016; Winnig, 2016).

In terms of the typical demonstration of intelligent manufacturing, Germany and the US spared no effort in demonstrating and promoting their development strategy to transform and upgrade their manufacturing industries. To a large extent, the demonstration and promotion of cross-industry, chain-wide, and comprehensive system solutions from multinational enterprises such as Siemens, SAP, and GE enable these enterprises to take a leading position in the restructuring process of global industry chains, value chains, and ecosystems. For example, the Germany Amberg factory is a model of an intelligent plant of the Siemens company. At Amberg, the real factory is operated together with the virtual factory, and the real factory data and production environments are reflected by the virtual factory, through which people can manage and control the real factory. Nearly $75 \%$ of the production operations have been automated. Products can communicate with the production equipment. IT systems take the role of controlling and optimizing all processes, ensuring a 99.9988\% product qualification ratio. Compared to 1989 when the factory was first built, the number of employees remains basically unchanged, while production capacity has been increased by eight times, and the error rate per processing of a million electronic products has reduced to $1 / 40$.

\subsection{Domestic development}

The manufacturing industry in China is facing a critical and historical moment in terms of the transformation from low end to the middle and high end of the value chain, from manufacturing giant to manufacturing power and from 'made in China' to 'created in China'. The Chinese government has proposed strategic plans of 'Made in China 2025', 'Guidance of the State Council on Promoting Internet+ Action', "Guidance of the State Council on Deepening Integration of Manufacturing and Internet", and the "13th Five-Year Plan on National Program for Science and Technology Innovation' to support the transformation. 'Made in China 2025' has clarified the strategic goals, guidance, and road map for 30 years, three steps and three stages to raise the country's manufacturing power. It sets the principles for becoming the second tier of the powerhouse in manufacturing: innovationdriven, quality first, environment-friendly development, structural optimization, talent-centric, as well as the strategic road maps: stick to the new model road to industrialization with Chinese characteristics, with the theme of innovative development, the focuses on enhancing quality and improving economic benefits, the main aim of accelerating deep penetration between new-generation informative techniques and manufacturing, and the highlights on smart manufacturing. The following are included therein:

Nine missions: (1) increasing innovative capability in national manufacturing, (2) promoting the deep fusion of information and industrialization, (3) strengthening the basic industry capacity, (4) booming the quality brand-building, (5) popularizing environment-friendly manufacturing, (6) advancing breakthroughs in key areas, (7) pushing forward further the structural adjustment to the manufacturing industry, (8) advancing services for manufacturing and production, and (9) increasing international involvement in manufacturing.

Ten major development fields: (1) the newgeneration information and communication technologies industry, (2) advanced numerically controlled machine tools and robots, (3) aviation and aerospace equipment, (4) ocean engineering equipment and high-tech marines, (5) railway transportation equipment, (6) energy-saving and new energy vehicles, (7) electric power equipment, (8) new materials, (9) biomedicine and high performance medical apparatus, and (10) agricultural equipment and machinery.

Five major programs: (1) a national innovation center construction program for the manufacturing industry, (2) a program of strengthening the industrial base, (3) deep integration of information technology and the industrialization program, (4) an environment-friendly manufacturing program, and (5) a high-end equipment innovation program. 
Eight strategic supports and assurance: (1) strengthening reform in governance and administrative mechanisms, (2) building a fair competitive market environment, (3) improving financial support policies, (4) enhancing fiscal and tax policy support, (5) perfecting multi-level training systems for talent, (6) improving policies on small and micro businesses, (7) opening up further the manufacturing industry, and (8) enhancing the organizational mechanisms for implementation.

China has witnessed encouraging progress in technologies, industry, and applications in terms of intelligent manufacturing in recent years.

With regard to intelligent manufacturing technology, China first proposed models, approaches and forms of intelligent manufacturing based on cloud manufacturing in 2009 (Li et al., 2010). Its achievements have been popularly referred to, and recognized by, the international academic community (Ren et al., 2013). Furthermore, key areas of intelligent manufacturing have made significant breakthroughs, such as high-end computerized numerical control (CNC) machine tools, industrial robots, intelligent instruments, and additive manufacturing, establishing an initial intelligent manufacturing standard system (Miao, 2016).

With regard to intelligent manufacturing industry development, network infrastructure has stepped into a higher level and, according to Miao (2016), breakthroughs have been made in high performance computing, networking communication equipment, intelligent terminals, and software, forming a series of mobile Internet, big data, and cloud computing leading enterprises, which support the development of intelligent manufacturing. In the field of intelligent products and intelligent Internet product development recent breakthroughs include products and services such as intelligent hardware and the Internet of Vehicles. Taking intelligent hardware devices as an example, the volume of global retail market for wearable smart equipment is 72 million in 2015, with an increase of $132 \%$ compared with that in 2014 . The overall volume is expected to reach 196.9 million by 2020, and compared to 179000 in 2013, the annual growth rate will be $25 \%$. As for China, market volume was 4.3 million units in 2014, growing to 16.8 million units in 2015. Close to $1 / 4$ of the global market volume, the growth rate in China is significantly higher than the global average.
Thanks to typical demonstrations of intelligent manufacturing, intelligence levels have been improving in key areas such as research and development design, production equipment, process management, logistics and distribution, and energy management. According to Miao (2016), the penetration rate of digital design tools in key industries is over $85 \%$. In recent years, Chinese enterprises such as China Aerospace Science and Industry Corp., Qingdao Haier Group, and Red Collar Group have implemented intelligent manufacturing applications. Taking CASIC as an example, CASICloud, the first cloud manufacturing platform, has been on-line for over a year, attracting more than 230000 registrations and releasing over 43 billion CNY CASIC business demands regarding all aspects of the manufacturing industry. Over 1000 innovation and entrepreneurship projects have been released on-line, and cooperation with international intelligent manufacturing and scientific services is underway.

In general, however, the manufacturing industry in China is facing some arduous challenges, and we need to accelerate 'five transformations': (1) the transformation from a technology follower to an independent developer and then a technology leader; (2) from traditional manufacturing to digital, network, and intelligent manufacturing, (3) from extensive manufacturing to high quality and efficient manufacturing, (4) from resource consumption and environment pollution manufacturing to green manufacturing, and (5) from production manufacturing to production+service manufacturing. Intelligent manufacturing in our country is still in the beginning stages in terms of application technology, industrialization, and application. The recently released 'Intelligent Manufacturing Development Plan’ (2016-2020) of China pointed out that:

"The manufacturing industry in China is in a phase of imbalanced development among different regions, industries, and enterprises, where mechanization, electrification, automation, and digitization co-exist. Development of intelligent manufacturing faces many problems: key common technology and core equipment being controlled by other countries; the weak security basis of the intelligent manufacturing standard, software, network, and information; immature new modes of intelligent manufacturing; insufficient supply of systemic and holistic solutions; lack of international leading enterprises and intelli- 
gent manufacturing talents of interdisciplinary integration. Compared with developed countries, China faces a more complicated environment, severe situation, and arduous tasks in the efforts of advancing the transformation of our intelligent manufacturing industry."

\section{Research direction of Al 2.0 in intelligent manufacturing industry}

From the perspective of application technology, industry development and application demonstration, we propose the following research directions for the application of AI 2.0 in the intelligent manufacturing industry.

\subsection{Application technologies of intelligent manu- facturing}

Based on the deep integration of AI 2.0 technology, manufacturing science and technology, information communication science and technology, and manufacturing application technology in the manufacturing industry, this research focuses on the follow aspects of intelligent manufacturing application technologies:

1. General technology of intelligent manufacturing systems, including intelligent manufacturing framework technology, SDN network system framework technology, air-space-ground integrated system framework technology, business models of intelligent manufacturing service, enterprise modeling and simulation technology, system development, application and implementation technology, intelligent manufacturing security technology, intelligent manufacturing assessment technology, and intelligent manufacturing standardization technology.

2. Intelligent manufacturing system platform technology: big data of intelligent manufacturing based network technology, intelligent resources/ capacity perception, Internet of Things; intelligent resources/capacities virtualization and service technology; construction/management/assessment technology for intelligent service; management, analysis and mining of intelligent knowledge/model/big data; technology for intelligent man-machine interaction; swarm intelligence design technology; intelligent design technology based on big data and massive knowledge; man-machine hybrid intelligent production technology; intelligent experiment technology that combines vitality and reality; intelligent management technology of independent decision-making; intelligent support technology with online service and remote support.

3. Intelligent design, production, management, experiment, support, and other key technologies involved in the entire circle of intelligent manufacturing, including: intelligent cloud innovation design technology, intelligent cloud product design technology, intelligent cloud production equipment technology, intelligent cloud operation and management technology, intelligent cloud simulation and experiment technology, and intelligent cloud service and support technology.

\subsection{Development of the intelligent manufacturing industry}

Intelligent products and intelligent interconnected products are to be researched.

As for intelligent manufacturing enabling tools, the following research needs to be conducted: intelligent industrial software including system software, platform software, and application software, as well as intelligent hardware that supports intelligent design, production, test, and assurance, including intelligent material, intelligent sensors, intelligent equipment, intelligent robots, new-generation intelligent network devices, service-oriented SDN control platforms, and new network evaluation systems.

Intelligent manufacturing systems need to be developed and operated on different layers, including intelligent manufacturing unit, intelligent workshop, intelligent factory, and intelligent industry, to support innovative manufacturing models, including process intelligent manufacturing, discrete intelligent manufacturing, networked collaborative manufacturing, and remote diagnosis and maintenance services.

\subsection{Typical paradigms of intelligent manufactur- ing}

Demonstrations to be researched and implemented include model-driven intelligent collaborative manufacturing across enterprises (businesses), knowledge-driven enterprise cloud services of intelligent manufacturing, human-machine-material cooperative intelligent workshop cloud, autonomous 
intelligent manufacturing units. At the same time, demonstrations need to be promoted and applied in key areas:

1. Paradigm of model-driven intelligent collaborative manufacturing across enterprises. As for model-driven intelligent collaborative manufacturing across enterprises (businesses), the cloud pool of all kinds of manufacturing resources/capacities needs to be built, and intelligent cloud technology needs to be used to automatically match demands and requirements of resources/services and realize selfconstruction, management, operation, and evaluation of the service environment. Operation centers of intelligent manufacturing cloud platforms need to be built to support model-driven, collaborative, full life cycle activities such as $\mathrm{R} \& \mathrm{D}$, production, management, logistics, and supportive services.

2. Paradigm of knowledge-driven cloud service for enterprises. As for knowledge-driven enterprise cloud services, which are based on integration, management, analysis, and mining of enterprise data, models, and knowledge, the operation center of the enterprise cloud platform needs to be built to provide enterprise services such as intelligent design, modeling and simulation, testing, production, management, supply chain, logistics, sales, 3D printing, and comprehensive assurance to support full life cycle activities.

3. Paradigm of human-machine-material cooperative workshop cloud. Human-machine-material cooperative workshop cloud uses technologies and products such as human-machine-material cooperative intelligent robots, intelligent optimization technology for processing code, intelligent equipment assurance, intelligent monitoring, intelligent logistics, cloud quality assurance, cloud management, and cloud scheduling to build intelligent equipment, production lines, processing control and workshop decision-making systems to achieve the integration of human, machine, and material with the help of an intelligent workshop operation center.

4. Paradigm of autonomous intelligent manufacturing units. Autonomous intelligent manufacturing units use technologies and products such as intelligent manufacturing distribution and planning based on advanced autonomous unmanned systems, online inspections, parts recognition and positioning, accident alarming to build intelligent devices, processing equipment, online monitoring systems, intelligent workplaces, security alarm systems, and automatic loading and unloading devices, with the help of a control center based on an advanced autonomous unmanned system.

Breakthroughs need to be made in technologies of full life cycle activity, full processes and flow intelligence including intelligent design, production, management, testing, and assurance based on AI 2.0 according to the requirements of developments in full life cycle activities and processes. Demonstrations to be developed and implemented include customizable and innovative designs based on Internet swarm intelligence, collaborative $\mathrm{R} \& \mathrm{D}$ spaces, intelligent cloud production, intelligent collaborative assurance, and supply/marketing/service chains, and need to be promoted and applied in key industries:

1. Paradigm of Internet-based swarm intelligence customized innovative design. As for customertailored and innovative design based on Internet swarm intelligence demonstrations, products and technologies such as collaborative innovation and design and tailored applications are used to build a customer-tailored and innovative design platform based on Internet swarm intelligence, enabling cloudswarm-intelligence-based product selection, experience, user involvement in design, and real-time tracking in key industries.

2. Paradigm of collaborative R\&D swarm intelligent space. Collaborative R\&D space demonstration uses collaborative, parallel, and integrated system methods to build a swarm intelligence space that supports big data processing, knowledge collaboration, and innovation aggregation. It develops various types of collaborative R\&D space focusing on important industries, enterprises, and individual users, and encourages these users to collaborate on R\&D challenges through Internet crowd sourcing, spreading out R\&D tasks.

3. Paradigm for intelligent plant production. Big data and massive knowledge-based intelligent technology may help realize intelligent scheduling and planning, process parameter optimization, intelligent logistics management and control, product quality analysis and improvement, preventive maintenance, production cost analyses and estimates, energy consumption monitoring and intelligent allocation, monitoring of production processes and procedures, and 
comprehensive workshop performance analysis and assessment for the entire production circle. The establishment of a plant operation control center and an intelligent scheduling system may facilitate the realization of flexible, preemptive cloud manufacturing to accelerate the production process and implement intelligent management over the enterprise and production. Intelligent processes of perception, machine learning, and cross-media may enable autonomous decision-making to support production optimization that combines the virtual and reality.

4. Paradigm of intelligent collaborative assurance and supply/marketing service. A knowledgedriven collaborative assurance and supply/marketing/ service platform needs to be constructed to collect logistics, supply chains, and warehouse and marketing data. The data will then be analyzed with big data technology to optimize path planning for supply chain logistics, and to improve refined logistics and precision marketing through pre-delivery, front warehouse and matching analysis of user needs and product characteristics.

\section{References}

Drath, R., Horch, A., 2014. Industrie 4.0: hit or hype? IEEE Ind. Electron. Mag., 8(2):56-58. http://dx.doi.org/10.1109/MIE.2014.2312079

Evans, P.C., Annunziata, M., 2012. Industrial Internet: Pushing the Boundaries of Minds and Machines. General Electric. http://www.ge.com/docs/chapters/Industrial_Internet.pdf

Ivanov, D., Dolgui, A., Sokolov, B., et al., 2016. A dynamic model and an algorithm for short-term supply chain scheduling in the smart factory industry 4.0. Int. J. Prod. Res., 54(2):386-402. http://dx.doi.org/10.1080/00207543.2014.999958

Lasi, H., Fettke, P., Kemper, H.G., et al., 2014. Industry 4.0. Business Inform. Syst. Eng., 6(4):239-242. http://dx.doi.org/10.1007/s12599-014-0334-4
Lee, J., Bagheri, B., Kao, H.A., 2015. A cyber-physical systems architecture for Industry 4.0-based manufacturing systems. Manuf. Lett., 3:18-23.

Li, B.H., Zhang, L., Wang, S.L., et al., 2010. Cloud manufacturing: a new service-oriented networked manufacturing model. Comput. Integr. Manuf. Syst., 16(1):1-7.

Li, B.H., Zhang, L., Chai, X.D., et al., 2014. Smart cloud manufacturing (cloud manufacturing 2.0) - a new paradigm and approach of smart manufacturing. Proc. Int. Intelligent Manufacturing Conf., p.26.

Li, P., 2016. Accelerate the construction and application of industrial intelligent cloud platform. High Technol. Ind., (5):84-88 (in Chinese).

Miao, W., 2016. Speech at the National Meeting to Exchange Pilot and Demonstration Experiences on Intelligent Manufacturing (in Chinese). http://mt.sohu.com/20160728/n461524353.shtml

National Manufacturing Strategy Advisory Committee (NMSAC), Strategy Advisory Center of the Chinese Academy of Engineering (SACCAE), 2016. Intelligent Manufacturing. Publishing House of Electronics Industry, Beijing (in Chinese).

Pan, Y.H., 2016. Heading toward artificial intelligence 2.0. Engineering, 2(4):409-413. http://dx.doi.org/10.1016/J.ENG.2016.04.018

Posada, J., Toro, C., Barandiaran, I., et al., 2015. Visual computing as a key enabling technology for industrie 4.0 and industrial Internet. IEEE Comput. Graph. Appl., 35(2):26-40. http://dx.doi.org/10.1109/MCG.2015.45

Ren, L., Zhang, L., Zhao, C., et al., 2013. Cloud manufacturing platform: operating paradigm, functional requirements, and architecture design. ASME Int. Manufacturing Science and Engineering Conf. collocated with the 41st North American Manufacturing Research Conf., p.1-10. http://dx.doi.org/10.1115/MSEC2013-1185

Wang, X.W., 2015. Industry 4.0: Road to the Future Industry of German Manufacturing Industry 2025 (Diagram). China Machine Press, Beijing (in Chinese).

Winnig, L.W., 2016. GE's big bet on data and analytics. MIT Sloan Manag. Rev., 57:5.

Yang, T., 2015. Predix: the stage pillar of Industrial Internet. China Ind. Rev., (10):76-81 (in Chinese). 